\title{
Prevalence and Angiographic Characteristics of Coronary Ectasia in Adults: A Retrospective Study in a Tertiary Cardiac Centre of Nepal
}

\author{
Satish Kumar Singh ${ }^{1}$, Kiran Prasad Acharya ${ }^{1}$, Chandra Mani Adhikari ${ }^{1}$, Rikesh Tamrakar ${ }^{1}$, \\ Sanjay Singh K.C ${ }^{1}$, Sushant Kharel ${ }^{1}$, Yubaraj Limbu ${ }^{1}$
}

${ }^{1}$ Department of Cardiology, Shahid Gangalal National Heart Centre, Kathmandu, Nepal

\author{
Corresponding Author: Satish Kumar Singh \\ Department of Cardiology \\ Shahid Gangalal National Heart Centre, Kathmandu, Nepal. Phone: 9841675401 \\ Email: satishdr@yahoo.com \\ ORCID ID No: 0000-0002-4697-2302
}

Cite this article as: Singh S.K., Acharya K P., Adhikari C M., et al. Prevalence and Angiographic Characteristics of Coronary Ectasia in Adults: A Retrospective Study in a Tertiary Cardiac Centre of Nepal. Nepalese Heart Journal 2021; Vol 18(2), 11-14.

Submission date: $27^{\text {th }}$ March, 2021

Accepted date: $29^{\text {th }}$ July, 2021

\section{Abstract}

Background and Aims: Coronary artery ectasia is a relatively uncommon problem encountered during coronary angiography with the prevalence ranging from $1.2 \%$ to $4.9 \%$. Coronary artery ectasia and aneurysm both denote an arterial segment the dimension of which is larger than normal arterial segment, both have diameter greater than 1.5 times of normal. The length of dilate segment is greater than its width in ectasia while less in aneurysm. There is an overlap between risk factors of coronary artery ectasia and atherosclerosis. The clinical relevance in general, and the appropriate medical management of coronary artery ectasia specifically, is ill defined, as no randomised prospective studies exists. The study was conducted with an aim to estimate the prevalence of coronary artery ectasia and aneurysm as well as to study the angiographic characteristics of coronary artery ectasia and aneurysm undergoing in adult patients' coronary angiography in tertiary cardiac centre of Nepal. Methods: A retrospective study was conducted in Shahid Gangalal national heart centre, Nepal analysing the angiographic records from cardiac catheterization lab. A total of 447 patients who underwent coronary angiography and meet the inclusion criteria from July, 2019 to December, 2019 were included in the study. Any angiographic evidence of coronary ectasia and aneurysm, coronary artery involved and it's extent were analysed and recorded in the proforma. In addition, any associated evidence of coronary artery disease was analysed and recorded in the proforma.

Results: The findings of our study revealed the overall prevalence of Coronary Artery Ectasia (CAE) and Coronary artery Aneurysm as $2.6 \%$. Coronary ectasia was most prevalent in left anterior descending (LAD) artery (83.3\%), followed by RCA and left main in $66.7 \%$ and $16.7 \%$ respectively. In contrast, Coronary aneurysm was mostly seen in RCA (66.7\%) followed by LCX (33.3\%). In addition, the study also showed the frequency of localised ectasia as $50 \%$ and the association of significant coronary artery disease with coronary artery ectasia in $66.67 \%$.

Conclusion: CAE and aneurysm are rare phenomenon encountered in routine coronary angiography, with LAD and RCA being most commonly involved in CAE and coronary aneurysm respectively. CAE and aneurysm have significant association with the coronary artery disease.

Key Words: Angiography, Aneurysm, Atherosclerosis, Coronary artery disease, ectasia

DOI: https://doi.org/10.3126/njh.v18i2.40394

\section{Introduction}

Coronary artery Ectasia (CAE) or coronary artery aneurysm is one of the rarely encountered cardiovascular disorders with the incidence ranging from $1.2 \%$ to $4.9 \%$, where the aneurysmal dilatation of coronary artery occurs ${ }^{1}$. Coronary artery Ectasia (CAE) is defined as a diffuse dilatation that exceeds more than a third of the coronary artery length, with the diameter of the ecstatic segment 1.5 times greater than that of the adjacent normal segment ${ }^{2}$. Coronary artery aneurysm (CAA) is defined as coronary artery segment that exceeds the diameter of the normal adjacent coronary segment by 1.5 times and involves less than a third of the total length of the vessel $^{3,4}$. The terms coronary artery ectasia and coronary artery Aneurysm have historically been used interchangeably to describe aneurysmal dilatation of coronary arteries ${ }^{5}$.

It is believed that atherosclerotic plaque growth induced exaggerated vascular remodelling and enzymatic degradation of the extracellular matrix of tunica media of the coronary arteries is a key pathologic process for the development of coronary Ectasia ${ }^{6}$.

Atherosclerosis or vessel wall injury after a coronary intervention (balloon angioplasty, stenting, or atherectomy) is considered as the main etiologic factor responsible in adults while Kawasaki disease is a common cause in children or young adults ${ }^{7,8,9}$. 
Less common causes of coronary artery aneurysm include cocaine use and systemic infections 10 . Genetic susceptibility may also play a role in the causation of coronary artery aneurysm and coronary artery ectasia ${ }^{11}$.

Coronary artery aneurysms are then divided to saccular aneurysms if the transverse diameter exceeds the longitudinal diameter, and to fusiform aneurysms in the opposite case ${ }^{12}$. However, Markis et al has classified CAE into four types on the basis of extent of involvement as: Type 1 (diffuse ectasia with aneurysmal lesions in two vessels), Type 2 (diffuse ectasia in one vessel and discrete ectasia in another), Type 3 (diffuse ectasia in one vessel) and Type 4 (discrete ectasia in one vessel) ${ }^{13}$. The right coronary artery is usually the most affected artery $(40 \%)$ followed by the left anterior descending $(32 \%)$, and the left main being the least affected artery $(3.5 \%)^{14}$.

The clinical presentation of CAE and CAA ranges from angina chest pain secondary to insignificant narrowing, positive stress test or even acute coronary syndromes. Thrombus formation can occur in the ectatic segment ultimately leading to distal embolization, coronary artery spasm or rupture. Thus, the prognosis of CAE depends directly on the severity of the concomitant coronary artery disease ${ }^{15}$.

We aim to study the prevalence and angiographic characteristics of coronary artery ectasia and coronary artery aneurysm in adult patients undergoing coronary angiography in National heart centre of Nepal.

\section{Methods}

A retrospective study was done in Shahid Gangalal National Heart Centre, where detailed study of angiographic records of 447 patients from Cardiac catheterization laboratory performed between July, 2019 to December, 2019 were included in the study. Angiographic records of all patients more than 19 years old age, complete records, and proper quality to review were included in the study.

Coronary artery Ectasia (CAE) is defined as diffuse dilation that exceeds more than a third of the coronary artery length, with the diameter of the ectatic segment 1.5 times greater than of adjacent normal segment.

Coronary artery aneurysm (CAA) is defined as coronary artery segment that exceeds the diameter of the normal adjacent coronary segment by 1.5 times and involves less than a third of the total length of the vessel.

We defined significant angiographic lesions as stenosis causing a more than or equal $70 \%$ luminal reduction in comparison to that of the normal reference segment.

\section{Statistical Analysis}

The collected data were stored in an electronic database (MSExcel Sheet). Statistical analyses were performed with statistical software (SPSS 22.0 for Windows).

P-value was calculated under the predetermined level of significance (0.02) and Confidence Interval (CI) of 98\% was constructed. Results were expressed as percentages, mean +/ standard deviation and median for variables.

\section{Results}

In our study coronary angiographic records of total 447 patients were analysed retrospectively. Out of them 302 were male $(67.6 \%)$ and 145 were female $(32.4 \%)$ with the age of the patients ranging from 21 to 99 years and mean age being 58.8 years (SD 12.312). The distribution of patients in different age groups is shown is table 1 .
Table 1: Distribution of patients in different age groups

\begin{tabular}{|c|c|c|}
\hline Age group & Frequency & Percentage \\
\hline$<=40$ & 40 & 8.9 \\
\hline $41-60$ & 191 & 42.7 \\
\hline $61+$ & 216 & 48.3 \\
\hline Total & 447 & 100.0 \\
\hline
\end{tabular}

Among the 447 patients, Coronary ectasia was present in 6 patients $(1.3 \%)$. The findings of our study revealed that coronary ectasia was most prevalent in left anterior descending (LAD) artery $(83.3 \%$ ), followed by RCA and left main in $66.7 \%$ and $16.7 \%$ respectively. Also, Coronary ectasia was mostly seen in single vessel $(50 \%)$, followed by double vessel $(33.3 \%)$ and single vessel $(16.7 \%)$ as shown in Table 2.

The results of our study revealed that Coronary artery aneurysm was present in 6 patients (1.3) among the 447 patients who were included in the study. Saccular aneurysm was present in 3 patients $(50 \%)$ and fusiform aneurysm was present in another 3 patients (50\%). Coronary aneurysm was mostly seen in RCA (66.7\%) followed by LCX $(33.3 \%)$. Unlike coronary ectasia, all the patients who had coronary artery aneurysm had involvement in single vessel only.

Among the patients who had coronary artery ectasia, significant coronary artery disease (CAD) was seen in $83.3 \%$ and was most commonly seen in LAD $(80 \%)$. Double vessel disease was seen in $80 \%$ of patients followed by single vessel disease in $20 \%$. The vessel involvement pattern and distribution of coronary artery disease in patients who had coronary artery ectasia are shown in table 2 and 3 .

Table 2: Vessel involvement pattern in coronary ectasia

\begin{tabular}{|l|l|l|}
\hline \multirow{2}{*}{ Involved vessel } & LAD & $5(83.3 \%)$ \\
\hline & RCA & $4(66.7 \%)$ \\
\hline & Left main & $1(16.7 \%)$ \\
\hline \multirow{2}{*}{$\begin{array}{l}\text { Number of vessels } \\
\text { involved }\end{array}$} & Single vessel & $3(50 \%)$ \\
\hline & Double vessel & $2(33.3 \%)$ \\
\hline & Triple vessel & $1(16.7 \%)$ \\
\hline
\end{tabular}

Table 3: Coronary ectasia with coronary artery disease

\begin{tabular}{|l|l|l|}
\hline $\begin{array}{l}\text { Frequency of } \\
\text { Coronary ectasia } \\
\text { with CAD }\end{array}$ & Present & $5(83.3 \%)$ \\
\hline & Absent & $1(16.7 \%)$ \\
\hline Involved vessel & LCX & $4(80 \%)$ \\
\hline & RCA & $2(40 \%)$ \\
\hline $\begin{array}{l}\text { Type of vessel } \\
\text { involved }\end{array}$ & $\begin{array}{l}\text { Double vessel } \\
\text { disease }\end{array}$ & $3(60 \%)$ \\
\hline & $\begin{array}{l}\text { Single vessel } \\
\text { disease }\end{array}$ & $4(80 \%)$ \\
\hline
\end{tabular}

In contrast, association of CAD in patients with coronary artery aneurysm revealed significant CAD present in $50 \%$ of patients who has CAE. Triple vessel disease was most commonly seen in those patients (66.7) followed by double vessel disease in 33.3. All the patients of coronary artery aneurysm associated with coronary artery disease had involvement of LAD and RCA. The vessel involvement pattern and distribution of coronary artery disease in patients with coronary artery aneurysm are shown in table 4 and 5. 
Table 4: Vessel involvement pattern in coronary aneurysm

\begin{tabular}{|l|l|l|}
\hline \multirow{2}{*}{ Involved vessel } & RCA & $4(66.7 \%$ \\
\hline $\begin{array}{l}\text { Number of vessels } \\
\text { involved }\end{array}$ & LCX & $2(33.3 \%$ \\
\hline
\end{tabular}

Table 5: Coronary aneurysm with CAD

\begin{tabular}{|c|c|c|c|}
\hline \multirow{2}{*}{$\begin{array}{l}\text { Frequency of } \\
\text { coronary aneurysm } \\
\text { with CAD }\end{array}$} & \multicolumn{2}{|c|}{ Present } & $3(50 \%)$ \\
\hline & \multicolumn{2}{|c|}{ Absent } & $3(50 \%)$ \\
\hline \multirow{3}{*}{ Involved vessel } & LAD & & $3(100 \%)$ \\
\hline & RCA & & $3(100 \%)$ \\
\hline & LCX & & $2(66.7 \%)$ \\
\hline \multirow{2}{*}{$\begin{array}{l}\text { Type of vessel } \\
\text { involvement }\end{array}$} & $\begin{array}{l}\text { Triple } \\
\text { disease }\end{array}$ & vessel & $2(66.7 \%)$ \\
\hline & $\begin{array}{l}\text { Doubl } \\
\text { disease }\end{array}$ & vessel & $1(33.3 \%)$ \\
\hline
\end{tabular}

The overall prevalence of CAE and CAA was $2.6 \%$ (12 patients) and males were most commonly affected compared to females $(75 \%$ in males and $25 \%$ in females). Marks Classification type I was seen in $25 \%(n=3)$ and type III were found in $25 \%(n=3)$. Localized ectasia was seen in $50 \%(n=6)$ of cases, of which $25 \%(n=3)$ were Saccular and $25 \%(\mathrm{n}=3)$ were Fusiform in character.

There were $66.67 \%(n=8)$ with associated significant coronary artery disease and $33.33 \%(\mathrm{n}=4)$ without Coronary obstruction.

\section{Discussion}

Coronary artery ectasia and aneurysm develops secondary to the altered vascular remodelling and has strong association with the atherosclerotic plaque growth ${ }^{16}$. The most important pathophysiological mechanism is the enzymatic degradation of the extracellular matrix ${ }^{17}$.

The overall prevalence of coronary artery ectasia in our study is $1.3 \%$. In different studies done throughout the world the prevalence is ranges from 1.2 to $4.9 \%$. The findings of our study are in contrast to the study done by Ahmed et al where the overall prevalence of coronary artery ectasia in north Indian population was $4.1 \%{ }^{18}$. However, the study done in Pakistan by Sultana et al the prevalence was $1.5 \%$, almost similar to the results of our study ${ }^{19}$.

The involvement of coronary artery and the number of vessels involved also varies in different studies. The results of our study revealed that the coronary artery ectasia was mostly seen in LAD and around $50 \%$ had involvement of more than one vessel. In contrast the localised coronary artery aneurysm was mostly seen in RCA and there were no Multivessel involvement. In a study done by Nyamu et al relatively high prevalence of isolated coronary ectasia with predominant involvement of the right coronary vessel was seen when diffuse and the left anterior descending artery when discrete ${ }^{20}$. Also, in a study done by ahmed et al, CAE was most frequent in RCA. However, localized aneurysm formation rather than diffuse ectasia was seen predominantly in LAD ${ }^{18}$. The same pattern was observed in a recent study from South India. ${ }^{20}$ However, another study from Pakistan revealed contrary findings, in which both diffuse ectasia and focal disease were more common in RCA. ${ }^{19}$

It is widely accepted fact that coronary artery ectasia and aneurysm has strong association with atherosclerotic cardiovascular disease or coronary artery disease as both share a common pathophysiology. Significant coronary artery disease was seen in $83 \%$ of patients with coronary ectasia and $50 \%$ of patients with coronary aneurysm. Also, the most common pattern of involvement was double vessel disease in those with CAE and CAD whereas triple vessel disease was common pattern seen in those with Coronary artery aneurysm and CAD. In study done by Harikrishnan S et al. and Lam et al. also showed the similar results with the coexistent CAD in those with CAE seen in $84.7 \%$ and $82 \%$ respectively ${ }^{21,22}$. However, The RCA was most commonly affected and most patients had single vessel involvement in the study done by Lam et al. ${ }^{22}$ The presence of concomitant CAD determines the prognosis of Coronary artery ectasia and aneurysm ${ }^{23}$. The medical management of CAE and aneurysm is not adequately addressed in the literatures till date unlike the treatment of atherosclerotic CAD. The presence of significant CAD in patients with CAE doesn't need any extra treatment other than that for $\mathrm{CAD}$, whereas in patients with isolated $\mathrm{CAE}$ and aneurysm, the prognosis is better and only treatment may be required are antiplatelets ${ }^{24}$.

The modality of revascularization for the ectasia with coronary artery disease lacks significant data. Drug-eluting balloon-expandable stents and self-expanding stents (SESs) are usually used. SESs permit to obtain a complete apposition of stent struts by its constant gentle outward force. Newer generation SES STENTYS stent made from nitinol with nickel-titanium alloy self-expands and confirms to vessel lumen over time ${ }^{25}$. The covered balloon-expandable Jostent has been shown to be an effective device for exclusion of coronary aneurysms. ${ }^{26}$

The overall prevalence of CAE and aneurysm was significantly higher in males (75\%). The findings of our study were almost similar to the study done in Singapore by Lam et al where the majority (74\%) were males $^{22}$. As the disease shares the common pathophysiological basis with the atherosclerotic coronary artery disease, the male sex predisposition can be easily hypothesised.

Our study has few limitations. Firstly, it's a retrospective and single centred study. Also, the association of CAE and aneurysm with the risk factors like diabetes, chronic kidney disease; congenital cases of CAE are not studied and identified and hence is the major limitation of our study. More multicentred and prospective studies are needed to get the clear overview of the condition.

\section{Conclusion}

Coronary artery ectasia and coronary artery aneurysm are relatively uncommon entities encountered during routine coronary angiography with the overall prevalence of $2.6 \%$. The study revealed that the most common involved vessel in CAE and aneurysm are LAD and RCA respectively. Atherosclerosis is the key pathophysiological mechanism and hence they have strong association with coronary artery disease, which determines the prognosis too.

\section{Source of funding \\ None}

\section{Conflict of interest}

None 


\section{References:}

1. Devabhaktuni S, Mercedes A, Diep J, Ahsan C. Coronary artery ectasia-a review of current literature. Current cardiology reviews. 2016 Nov 1;12(4):318-23. https://doi.org/10.2174/1573403X12666160504100159 PMid:27142049 PMCid: PMC5304254

2. Aboeata As, Sontineni SP, Alla VM, Esterbrooks DJ. Coronary artery ectesia : current concepts and interventions. Front Biosci.2012;4(3):300-310. https://doi.org/10.2741/e377

3. Tunick PA, Slater J, kronzon I, Glassman E. Discrete atherosclerotic coronary artery aneurysms: a study of 20 patients. J Am Coll Cardiol.1990;15(2):279-282. https://doi.org/10.1016/S0735-1097(10)80049-X

4. Krueger D,Stierle U, Herrmann G, Simon R, Sheikhzadeh A. Exercise - induced myocardial ischaemia in isolated coronary artery ectasia and aneurysm ( dilated coronopathy"). J Am Coll Cardiol.1999;34(5):1461-1470. https://doi.org/10.1016/S0735-1097(99)00375-7

5. Kawsara A, Nunez Gil IJ, Alqahtani F, Moreland J, Rihal CS, Alkhouli M. Management of Coronary Artery Aneurysms. JACC Cardiovasc Intern 201; 11:1211-23. https://doi.org/10.1016/j.jcin.2018.02.041 PMid:29976357

6. Antoniadis AP, Chatzizisis YS, Giannoglou GD. Pathogenetic mechanisms of coronary ectasia. Int J Cardiol 2008; 130(3): 335- 43.

https://doi.org/10.1016/j.ijcard.2008.05.071 PMid:18694609

7. kawsara A, Nunez Gil IJ, Alqahtani F, Moreland J, Rihal CS, Alkhouli M. Management of Coronary Artery Aneurysms. JACC Cardiovasc Interv 2018; 11:1211-23. https://doi.org/10.1016/j.jcin.2018.02.041 PMid:29976357

8. Bavry AA,Chiu JH, Jefferson BK, et al . Development of coronary Aneurysm after drug-eluting stent implantation. Ann Intern Med 2007; 146:230-2. https://doi.org/10.7326/0003-4819-146-3-200702060-00146 PMid:17283357

9. Friedman KG, Gauvreau k, Hamaoka-Okamoto A, et al. Coronary Artery Aneurysms in Kawasaki Disease: Risk Factors for Progressive disease and Adverse Cardiac Events in the US Population. J Am Heart Assoc 2016;5:e003289. https://doi.org/10.1161/JAHA.116.003289

10. Baker DW, Whitehead NJ, Barlow M. Mycotic Coronary Aneurysms. Heart Lung Circ 2018; Dec 19: [ Epub ahead of print].

11. Abou Sherif S, Ozden Tok O, Taskoylu O, Goktekin O, Kilic ID. Coronary Artery Aneurysms: A Review of the Epidemiology, Pathophysiology, Diagnosis, and Treatment. Front Cardiovasc Med 2017; 4:24. https://doi.org/10.3389/fcvm.2017.00024 PMid:28529940 PMCid: PMC5418231

12. Kawsara A, Núñez Gil IJ, Alqahtani F, Moreland J, Rihal CS, Alkhouli M. Management of coronary artery aneurysms. JACC: Cardiovascular interventions. 2018 Jul 9;11(13):121123.

https://doi.org/10.1016/j.jcin.2018.02.041

PMid:29976357
13. Markis JE, Joffe CD, Cohn PF, Feen DJ, Herman MV, Gorlin R. Clinical significance of coronary arterial ectasia. Am J Cardiol 1976; 37(2): 217-22 https://doi.org/10.1016/0002-9149(76)90315-5

14. M. Syed, M. Lesch Coronary artery aneurysm: a review Prog Cardiovasc Dis, 40 (1997), pp. 77-84 https://doi.org/10.1016/S0033-0620(97)80024-2

15. 15. Ozcan OU, Gulec S. Coronary artery ectasia. Cor et Vasa. 2013 Jun 1;55(3): e242-7. https://doi.org/10.1016/j.crvasa.2013.01.003

16. Manginas A, Cokkinos DV. Coronary artery ectasias: Imaging, functional assessment and clinical implications. Eur Heart J 2006; 27:1026-31. https://doi.org/10.1093/eurheartj/ehi725 PMid: 16415301

17. Antoniadis AP, Chatzizisis YS, Giannoglou GD. Pathogenetic mechanisms of coronary ectasia. Int J Cardiol 2008; 130:33543.

https://doi.org/10.1016/j.ijcard.2008.05.071 PMid:18694609

18. Ahmed R, Khandelwal G, Bansal A, Jain A, Khandelwal $\mathrm{K}$, Singla R. Prevalence and clinical profile of angiographic coronary artery ectasia among North Indian population. J Nat Sc Biol Med 2019; 10:72-6 https://doi.org/10.4103/jnsbm.JNSBM_9_18

19. Sultana R, Sultana N, Ishaq M, Samad A. The prevalence and clinical profile of angiographic coronary ectasia. J Pak Med Assoc. 2011 Apr;61(4):372-5. PMID: 21465976.

20. Nyamu P, Ajit MS, Joseph PK, Venkitachalam L, Sugirtham NA. The Prevalence and Clinical Profile of Angiographic Coronary Ectasia. Asian Cardiovascular and Thoracic Annals. 2003;11(2):122-126. doi:10.1177/021849230301100207 https://doi.org/10.1177/021849230301100207 PMid:12878558

21. Harikrishnan S, Sunder KR, Tharakan J, et al. Coronary artery ectasia: angiographic, clinical profile and follow-up. Indian Heart J 2000; 52(5): 547-53.

22. Lam CSP, Ho KT. Coronary artery ectasia: a ten-year experience in a tertiary hospital in Singapore. Ann Acad Med Singapore 2004;33(4): 419-22.

23. Schmidt M, Paterick TE (2018) Coronary Artery Ectasia: An Interventional Cardiologist's Dilemma. Int Arch Cardiovasc Dis 2:007. doi.org/10.23937/iacvd-2017/1710007 https://doi.org/10.23937/iacvd-2017/1710007

24. Mavrogeni S. Coronary artery ectasia: from diagnosis to treatment. Hellenic J Cardiol. 2010 Mar 1;51(2):158-63.

25. Moretti $\mathrm{C}$, Omedè $\mathrm{P}$, Presutti DG, D'Ascenzo F, De Simone V, Colaci C, et al. Shaping an ectatic coronary artery: Stentys implantation. Int J Cardiol 2014; 171:459-61 https://doi.org/10.1016/j.ijcard.2013.11.056 PMid:24369794

26. Szalat A, Durst R, Cohen A, Lotan C. Use of polytetrafluoroethylene-covered stent for treatment of coronary artery aneurysm. Catheter Cardiovasc Interv 2005; 66:203-8.https://doi.org/10.1002/ccd.20448 PMid:15977267 